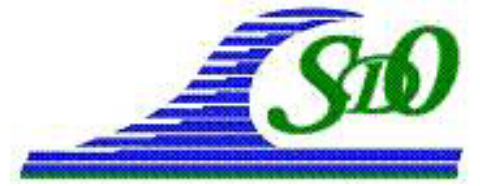

$X^{\text {èmes }}$ Journées Nationales Génie Côtier - Génie Civil

Les Sables d'Olonne, 22-25 juin 2010

DOI:10.5150/jngcgc.2010.096-O C Editions Paralia CFL

disponible en ligne - http://www.paralia.fr - available online

\title{
Durability properties of marine sediment stabilized by pozzolan and alkali activated binders
}

\author{
Makiko OBANA ${ }^{1}$, Daniel LEVACHER ${ }^{2}$, Philippe DHERVILLY ${ }^{3}$
}

1. Nagoya Hydraulic Research Institute for River Basin Management, Dept. of Civil Engineering, Nagoya University, Nagoya, Japan.

mobana@civil.nagoya-u.ac.jp

2. Université de Caen, Faculté des Sciences, UMR 6143 CNRS - M2C, Esplanade de la Paix, 14032 Caen, France.

daniel.levacher@unicaen.fr

3. ARD Normandie, 14000 Hérouville Saint-Clair, France.

pdhervilly@ard-normandie.fr

\begin{abstract}
:
The Mont-Saint-Michel Project has been carried out to restore the maritime characteristics to those that existed before 1995. Attempts have been made to use marine sediments that are produced as construction waste every year for purposes such as the construction of pavements and driveways; however, it is difficult to directly use the sediments for these purposes. Hence, methods to stabilize marine sediments have recently been developed. The purpose of this paper is to propose a new approach to sediments stabilization; in this approach, pozzolan and alkali-activated binders, are used. The freeze-thaw test and wet-dry test are conducted to determine the durability of the sediments and examine their suitability for use as construction material. The binders are prepared by alkali activation using pozzolan, and different amounts of the binders are mixed with marine sediments named "la tangue". The surfaces of one group of sediments are treated by a substance containing liquid glass. We compare the durability properties and deformation behaviors of two different types of specimens, by conducting tests and taking into consideration climatic conditions around northern France. The sediments stabilized by surface treatment showed high durability properties. The possibility of using them as construction sediments is discussed.
\end{abstract}

Keywords:

Durability - Marine sediment - Stabilization - Pozzolan - Alkali activation

\section{Introduction}

The Mont-Saint-Michel Project was launched to restore the maritime characteristics to those existing before 1995. With the increase in construction activities, large quantities of marine sediments are produced as construction waste every year. So far, the sediments have been reused only as an agricultural amendment; however, all the sediments generated cannot be consumed by use as an amendment. A new approach has 
been proposed for the valorization of the sediments (LECLERC, 2006). One of them is to reuse the sediments for purposes such as construction of pavements and driveways. Various methods for the solidification/stabilization $(\mathrm{S} / \mathrm{S})$ of marine sediments have recently been developed. In this study, we propose a new approach to sediments stabilization; in this approach, pozzolan and alkali-activated binders are mixed with sediments. Freeze-thaw and wet-dry tests are conducted for determining the durability of the mixture and to examine its suitability for reuse as construction material. The binders used in this study were proposed by the company ARD-Normandie (ARD, web site), which specializes in the treatment of surface soils. Initially, the binders are prepared by alkali activation using pozzolan, and subsequently, varying amounts of the binders are mixed with marine sediments named "la tangue." The surfaces of one group of sediments are treated by a substance containing liquid glass. The durability properties and deformation behaviors of two different types of specimens are compared by carrying out tests and taking into consideration the climatic conditions around northern France.

\section{Solidification and stabilization}

\subsection{Definition}

The use of solidification and stabilization techniques is widely considered to be a viable option for the treatment of many types of hazardous wastes. The development of specific formulations for different types of wastes began in the late sixties and early seventies.

The term solidification/stabilization is a generic term used to describe a wide range of techniques that can transform wastes into forms that are less environmentally harmful. This usually involves physical or chemical immobilization of the constituents of the wastes. In this study, we follow the definitions (BOUTOUIL, 1998) given below:

a) Solidification: It refers to the encapsulation of waste in a monolithic solid with high structural integrity, so that the physical characteristics of the waste are improved. It does not necessarily involve a chemical interaction between the wastes and the solid.

b) Stabilization: It refers to a reduction in the hazard potential of waste through the conversion of the contaminants into their least soluble, least mobile, or least toxic form. The physical nature and handling characteristics of the waste are not necessarily changed by this process.

The fundamental objectives of $\mathrm{S} / \mathrm{S}$ are to reduce the negative impact of wastes on the environment and to obtain a product with structural integrity.

\subsection{Stabilization of marine sediment: La tangue}

Marine sediment samples were obtained from the bay of Mont-Saint-Michel; these samples are called "la tangue". The samples with an abundance $(>50 \% \mathrm{CaCO} 3)$ of 
carbonates (LEMEE, 2006) were excavated from different areas around the bay. The sediments consisted of fine particles with a maximum diameter less than $100 \mu \mathrm{m}$ (table 1).

Table 1. Grain size distribution of sediment samples.

\begin{tabular}{lllll}
\hline Clay fraction $(\%,<2 \mu m)$ & Silty fraction $(\%, 2-64 \mu m)$ & $\boldsymbol{d}_{10}(\mu \mathrm{m})$ & $\boldsymbol{d}_{\mathbf{5 0}}(\mu \mathrm{m})$ & $\boldsymbol{d}_{\mathbf{9 0}}(\mu \mathrm{m})$ \\
\hline $22 \%$ & $78 \%$ & 0.5 & 5.4 & 26.2 \\
\hline
\end{tabular}

\subsection{Binders}

a) Pozzolan binder $-L P$ -

Fly ash and lime, which are the constituents of the pozzolan binder used in this study, are residues generated during the combustion of coal. They are generally obtained from chimneys of coal-fired power plants and mainly comprise $\mathrm{SiO}_{2}$ and $\mathrm{Al}_{2} \mathrm{O}_{3}$, respectively. Pozzolanic reaction of fly ash improves the various characteristics of sediments since in this reaction, water and fly ash are mixed with the sediments.

b) Alkali activation binder - $A A$ -

The alkali activation of industrial sub-products (especially residues that originate from mining activity and the energy sector) is a chemical process that is used to obtain new cement materials. In this study, the alkali activation of caustic soda with different compositions but a fixed concentration of $10 \mathrm{~mol}$ is carried out to produce new cement materials. The solution is prepared by dissolving $98 \% \mathrm{NaOH}$ pellets in water with pH 6.5.

\subsection{Curing products: VerreSol ${ }^{\circledR}$}

VerreSol is a curing substance that improves the resistance of sediments whose surfaces are treated with it; it also reduces the porosity of the sediments. It is liquid glass, and belongs to the geopolymer family. Geopolymerization is a general term to describe all the chemical processes that are involved when alumina silicates are reacted with aqueous alkaline solutions to produce a new class of inorganic binders called geopolymers.

\section{Experimental procedures}

Initially, the binders were prepared by alkali activation using pozzolan, and different amounts of the binders were mixed with marine sediments named "la tangue". One group of sediments were treated on their surface by a substance containing liquid glass. The durability properties and deformation behaviors of two different types of specimens were compared by taking into consideration the climatic conditions around northern France. 


\subsection{Definition of dosages}

The composition of sediment mixtures is specified as percentage of dry marine sediments. The concentration of the alkali used for the activation is defined as the ratio of the total number of $\mathrm{NaOH}$ ions to the total volume of free water contained in the mixture. Table 2 shows the amount of each constituent in the sediment mixtures. Two different types of mixtures - LP and AA — were prepared.

Table 2. Mixture of materials.

\begin{tabular}{lllll}
\hline Mixture & Reference & $\begin{array}{l}\text { Binders } \\
\text { dosage[\%] }\end{array}$ & [NAOH] dosage & $\begin{array}{l}\text { Total moisture } \\
\text { content [\%] }\end{array}$ \\
\hline Pozzolan binder & $L P$ & $8^{*}$ & - & 20 \\
Alcali Activation & AA & $8^{* *}$ & 4 mols & 20 \\
\hline * and** denote the presence of fly ash and lime, respectively, and the composition is that proposed by ARD (web site).
\end{tabular}

\subsection{Specimen preparation}

Specimens were prepared by mixing a specific amount of the dry marine sediment in a solution containing water and two types of binders for $2 \mathrm{~min}$. The freshly prepared mixture was poured into circular stainless steel molds with dimensions of $38 \times 75 \mathrm{~mm}$; the molds were filled to only one-third of their capacity. The mixtures in the molds were compacted by applying normal stress, and they were then filled to half of their remaining capacity. The mixtures were again compacted and the molds were then filled to capacity. Once again the mixtures were compacted. The specimens were then removed from the molds and were sealed in plastic cases and cured for $24 \mathrm{~h}$ at a temperature of $20^{\circ} \mathrm{C}$. At the same time, the surface of half of the specimens was treated with $3 \mathrm{~g}$ of a curing product called VerreSol. The treated specimens were referred to as "TS".

\subsection{Unconfined compression test and durability tests}

The unconfined compression test and two durability tests -freeze-thaw (F/t) and wet-dry $(\mathrm{W} / \mathrm{d})$ tests- were conducted.

\section{a) Unconfined compression (UC) test}

The primary purpose of this test is to determine the unconfined compressive strength, which is then used to calculate the unconsolidated shear strength of the sediment under unconfined conditions. In this study, it is conducted three times, 7, 14, and 28 days after the curing of the specimens.

b) Freeze-thaw test

This test (STEGEMANN \& COTE, 1991) is used to expose specimens to harsh $\mathrm{F} / \mathrm{t}$ cycling conditions. The specimens are first immersed in water at a temperature of $20 \pm$ $5^{\circ} \mathrm{C}$ in a vacuum for $24 \mathrm{~h}$ so that all the pores are filled with water. They are then placed 


\section{XI $I^{\text {èes }}$ Journées Nationales Génie Côtier - Génie Civil}

Les Sables d'Olonne, 22-25 juin 2010

in a freezer to reach a temperature of $10 \pm 1^{\circ} \mathrm{C}$, which corresponds to the thawing phase. After $7 \mathrm{~h}$, they are further cooled to the freezing phase, which corresponds to a relative temperature of $-10 \pm 1^{\circ} \mathrm{C}$, and maintained in this phase for $17 \mathrm{~h}$. For each specimen, 20 cycles are performed, with every cycle comprising one freezing and one thawing process. After 20 cycles, the UC test is conducted to compare the durabilities of specimens cured for different periods.

c) Wet-dry test

This test was conducted for the evaluation of the wetting and drying resistances of monolithic, solid, solidified/stabilized sediments (STEGEMANN \& COTE, 1992). The test involved 10 cycles; each cycle consisted of a wetting phase, in which the specimen was immersed in water at the ambient temperature for $24 \mathrm{~h}$, and the drying phase, in which the specimen was dried at $60^{\circ} \mathrm{C}$ for $24 \mathrm{~h}$. Subsequently, the W/d test and UC test were conducted.

A schematic representation of the experimental approach used in the present study is shown in figure 1.

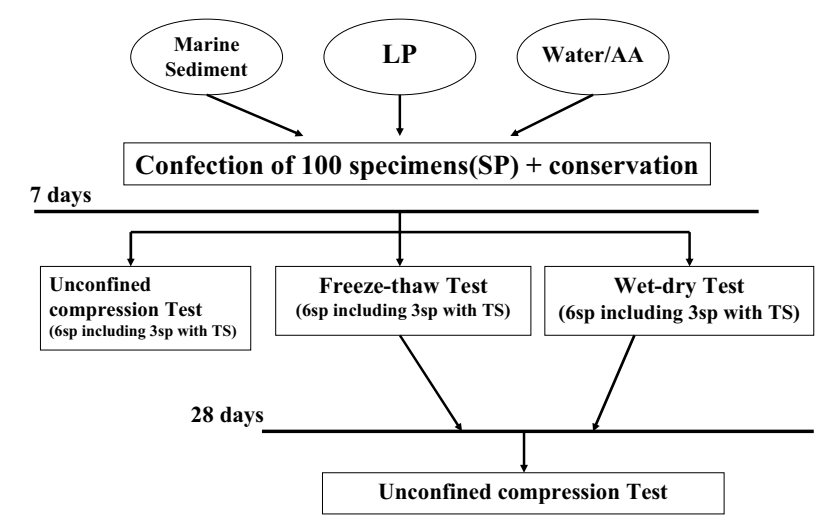

Figure 1. Outline of the experimental methodology.

\section{Results and Discussions}

\subsection{Mechanical properties}

The mass changes determined by conducting the F/t test are shown in figure 2 . We also observed the changes in the specimens. During the first cycle, the specimens did not show any degradation. After the first freezing phase, we observed small white lumps, which were solidified wastes, on the surface of each specimen. Below, we shall compare the mass changes for different mixtures. Observations of the surfaces of LP specimens showed that the first flakes (a few millimeters of fragments) dropped at the beginning of the third or fourth cycle in the case of specimens that were not treated with VerreSol (TS); in the case of specimens treated with TS, the first flakes dropped at the beginning of the sixth or twelve cycles. After the twelfth cycle, the condition, including mass, of the specimens was stable, as shown in figure 2 (a). This suggests that the 
strength of specimens is not affected by the laitance phenomena. The differences between specimens with and without TS were not significant, but surface treatment delayed surface deterioration. From the point of view of mass changes, the AA specimens were observed to show fragments in the $8^{\text {th }}$ and $11^{\text {th }}$ cycles, and therefore, there is a possibility of their breaking down into small fragments. Overall, these results showed that LP is better than AA.

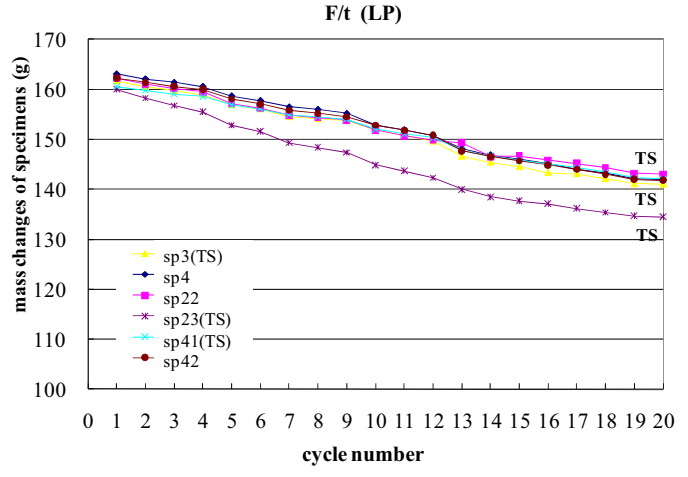

(a)

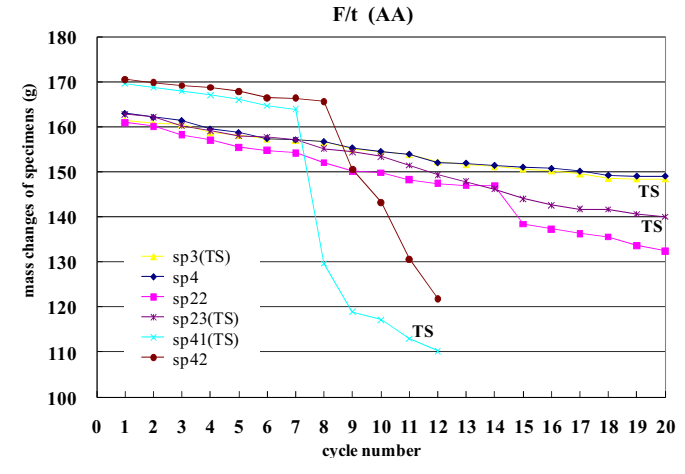

(b)

Figure 2. (a) Mass changes in LP specimens with and without TS treatment; the changes are determined by conducting the F/t test. (b) Mass changes in each specimen of AA with and without TS treatment; the changes are obtained by conducting the F/t test.

W/d (LP)

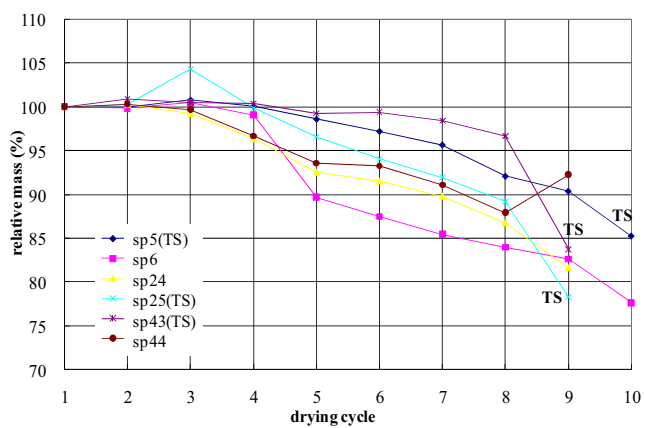

(a)

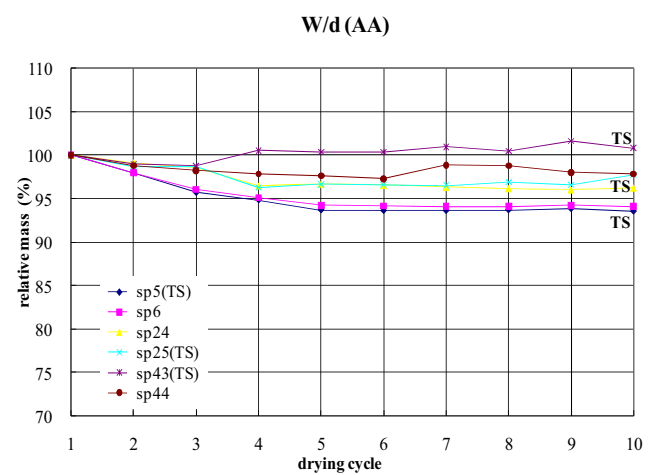

(b)

Figure 3. Mass changes in (a) LP and (b) AA specimens with and without TS treatment; the changes are determined by conducting the W/d test.

In the following section, we compare the conditions of specimens of the different mixtures by carrying out the $\mathrm{W} / \mathrm{d}$ test. The mass changes determined using the $\mathrm{W} / \mathrm{d}$ test are shown in figure 3. A part (few millimeters) of the first fragment dropped after four cycles in the case of specimens with pozzolan binders. Subsequently, the mass of the specimens decreased and their degradation advanced rapidly, as shown figure 3 (a). 
Two-third of the specimens could not last till the final cycle of this test. In the final phase, all specimens had been completely broken. Similar observations were made for the specimens treated with TS. On the other hand, figure 3 (b) shows that AA specimens had higher resistance than LP specimens. The mass loss rates were estimated to be $3-$ $7 \%$, which suggests that there were no changes. Fissures were formed in the specimens at the beginning of the drying phase. However, the first fissures did not damage the specimens. The above trends show that AA offers more advantages than LP. Surface treatment did not appear to have any effect on the specimen. Therefore, it can be considered that TS has no effect.

\subsection{Durability properties}

Figure 4 shows the result of a comparison of the compressive strengths of LP and AA specimens subjected to the $\mathrm{F} / \mathrm{t}$ and $\mathrm{W} / \mathrm{d}$ tests and those not tested; the specimens considered were those cured for 28 days. The results for LP specimens are shown in figure 4 (a). The pressure was found to vary from 1.2 to $1.9 \mathrm{MPa}$; the value for specimens subjected to the $\mathrm{F} / \mathrm{t}$ test was higher than that for the specimens that were not tested by $1.0 \mathrm{MPa}$. These results indicate that the influence of resistance on compressive strength varies with the condition of the atmosphere and depends on the conservation or treatment period. The surface treatment could not identify any new effect as mentioned above. The results for AA specimens are shown in figure 4 (b) and they indicate a negative correlation with the results of LP.

The value for specimens subjected to the W/d test was higher than those for the specimens subjected to the $\mathrm{F} / \mathrm{t}$ test and untested specimens by 0.3 and $1.2 \mathrm{MPa}$, respectively. Finally, the compressive strength values were varied from 0.8 to $1.1 \mathrm{MPa}$ for the two different types of specimens. The results showed that these values were sufficient for reusing the sediments for constructing pavements and driveways.

\section{Conclusions}

In this paper, the durability properties of marine sediments named "la tangue" that can be stabilized by pozzolan and alkali-activated binders were determined by conducting mechanical tests such as the $\mathrm{F} / \mathrm{t}$ and $\mathrm{W} / \mathrm{d}$ tests; in addition, the climatic conditions around northern France were also taken into consideration for the determination of the properties. The F/t test showed that the durability of sediments stabilized by pozzolan binders is greater than that of sediments stabilized by alkali-activated binders. On the other hand, marine sediments stabilized by an alkali-activated binder were observed to have better resistance under wet-drying conditions. Surface treatment of the sediments did not significantly enhance their compressive strength, but delayed their deterioration in the freezing and thawing phases in the freeze-thaw test. The possibility of the use of sediments as construction sediments has been discussed. 


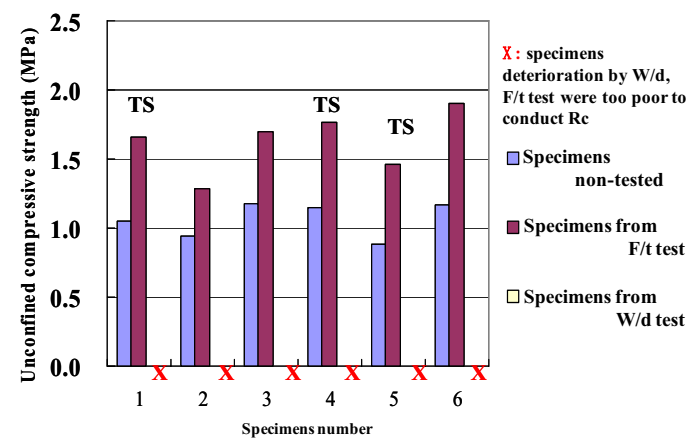

(a)

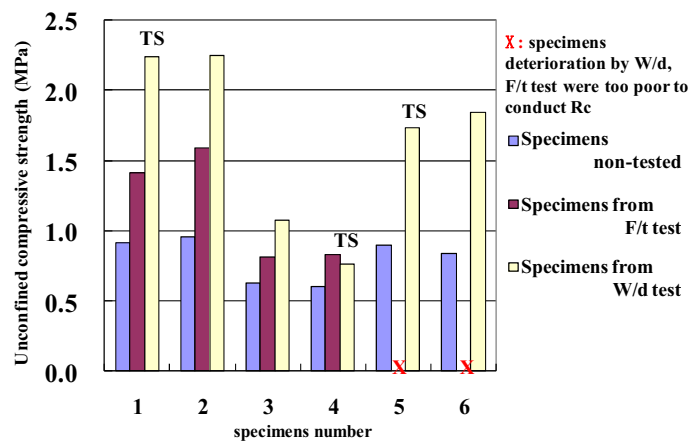

(b)

Figure 4. (a) Comparison of compressive strength of LP specimens subjected to the F/t and W/d tests and untested specimens after 28 days of curing. (b) Comparison of compressive strength of AA specimens subjected to the F/t and W/d tests and untested specimens after 28 days of curing.

\section{References}

ARD (web site). ARD, la référence des sols stabilisés naturels. http://www.ardnormandie.fr.

BOUTOUIL M. (1998). Traitement des vases de dragage par solidification/stabilisation à base de ciment et additifs. Thèse de Doctorat, Université du Havre, $276 \mathrm{p}$.

LECLERC M. (2006). Valorisation de la tangue, recherche de solutions et analyse technico-économique. Mémoire de stage ENTPE, DDE Manche, 98 p.

LEMEE F. (2006). Traitement par alcali activation de sédiments fins marins non contaminés et à faible teneur en eau - Mise au point d'un procédé de stabilisation. Thèse de doctorat, Université de Caen Basse-Normandie, 187 p.

STEGEMANN J.A., COTE P.L. (1991). Programme conjoint d'étude de méthodes d'essai pour l'évaluation des déchets solidifiés. Série de la protection de l'environnement SPE 3/HA/8, ENVIRONNEMENT Canada, 131 p.

STEGEMANN J.A., COTE P.L. (1992). Protocole d'évaluation proposé pour les déchets solidifiés à base de ciment. Série de la protection de l'environnement SPE 3/HA/8, ENVIRONNEMENT Canada, 49 p. 